ECONOMICS

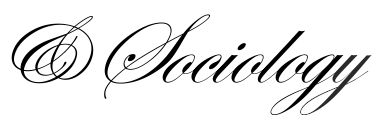

Received: November, 2017

1st Revision: December, 2017

Accepted: February, 2018

DOI: $10.14254 / 2071-$

789X.2018/11-1/2

Lechman, E. (2018). Networks Externalities as Social Phenomenon in the

Process ICT Diffusion. Economics and Sociology, 11(1), 22-43. doi:10.14254/2071-

789X.2018/11-1/2

\section{NETWORKS EXTERNALITIES AS SOCIAL PHENOMENON IN THE PROCESS ICT DIFFUSION}

\begin{abstract}
This paper is designed to fill the gap in knowledge that we have identified regarding the process of diffusion of information and communication technologies and emerging network effects that significantly enhance spread of these technologies. We contribute to the present state of the art by examining the process of ICT diffusion in 50 countries, which in 2015 achieved highest ICT penetration rates. With this aim we consider 2 core ICT indicators - mobile cellular telephony and Internet penetration rates; all statistical data are entirely extracted from World Telecommunications / ICT Indicators database 2016. In the research part we demonstrate ICT diffusion curves and examine elementary descriptive statistics to show how fast and pervasively information and communication technologies have evaded telecommunication markets. Next, relying on panel and dynamic panel models we verify the hypothesis on the existence of network effects that enhance rate of ICT diffusion. Our major findings confirm that across countries being in scope of our analysis, the process of ICT diffusion has been significantly attributed to strong network externalities.
\end{abstract}

Keywords: ICT, network effects, society.
JEL Classification: O33, A14, D80

\title{
Introduction
}

Technology and society are closely related. Technologies and technological changes are a complex and multidimensional phenomenon, predetermined by a variety of economic, social, political and institutional factors. No need to say that technology, which comprises the whole stock of human knowledge, is a fundamental element of long-term socioeconomic development (Rosenberg, 1974), although it is widely acknowledged that its impact on economy or society overall is neither immediate, nor direct. Mokyr (2005) in his studies provides multiple arguments in support of the thesis that technology is knowledge, and in his book 'The lever of riches: Technological creativity and economic progress' (Mokyr, 1992), he states that technology has an epistemological nature, suggesting that technology itself cannot exist outside people`s brains. In Fagerberg et al. (2010) and Comin et al. (2006) we find arguments that use and adoption of technology, similarly to knowledge, allows emerging the unique scaling effects brining benefits to all its users. Lechman (2015) and Rosenberg $(1974,1982)$ argue that technology and technological progress cover a wide range of human activities, which are 
essential elements of socioeconomic systems. Technological progress offers cutting-edge and profound changes to societies and economies. It deeply transforms the way individuals and the whole societies act; it enforces significant shifts and transformations, which often are revolutionary in their nature. Many technologies may be claimed as being "pervasive technologies", which means their adoption reshapes the present state of art and they are thoroughly implemented in social life. Undoubtedly, the socioeconomic impact of technology is put in a complex context involving not only time, but a wide range of social norms and attitudes, political regimes, legal and institutional frameworks, as well as geographical location and country`s historical legacy (Kling, 2000).

In the late 1980s, there emerged a debate contributing to our understanding of technology itself and technological progress. MacKenzie and Wajcman $(1985,1999)$ proposed the 'social shaping of technology' approach that allows seeing technology and technological progress from a different angle, and offers broader 'understanding of the relationship between scientific excellence, technological innovation and economic and social well-being' (Williams and Edge, 1996). The social shaping of technology concept is sometimes claimed as 'technological determinism' because 'technological development is autonomous with respect to society; it shapes society, but is not reciprocally influenced' (MacKay and Gillespie, 1992, p. 686). Evidently, technology must not be perceived as being purely deterministic (Mattsson, 2007), but technological changes are rather socially and institutionally embedded processes (Dicken, 2007), thus, the way technology is used is subject to the socioeconomic context. Without denying the fact that technology affects societies, it also works the other way round this is a society and its forces that determine the emergence and then the process of diffusion of new technological solutions.

For the several previous decades, since 1980 onwards, the world has been witnessing the explosive growth of new information and communication technologies. Widely available data on increasing ICT penetration rates suggests that nearly all countries in the world are included in this overwhelming process. Boosting demand for new technologies that offer 'a connection with an outside world' to societies are disruptively reshaping the world landscape. Many claim that ICT are the technologies "for all", so they diffuse unboundedly through the society especially in the countries that have been permanently suffering from technological underdevelopment. ICT are low-cost technologies that may be used even by low-income and poorly educated people. The empirical evidence found in the surveys by Lechman $(2015,2017)$ shows that ICT spread is a strongly endogenously driven process and ICT diffusion is probably mostly enhanced by the emergence of network effects (network externalities).

This paper is designed to contribute to the present state of art by verifying the hypothesis on the existence of network effects that may constitute an important factor enhancing dynamic process of ICT diffusion. The process of ICT spread is fast and it seems to omit all 'classical' barriers that 'old-type' technologies used to face. Keeping this in mind, this study is of crucial importance as it allows the reader finding out to what extent the process of ICT diffusion is distinct from what was observed worldwide with the previously emerged technological solutions. This study also allows confirming the general hypothesis that ICT is technologies for all, and its diffusion process is endogenously driven, being unrelated to other social, economic or institutional prerequisites.

With this aim we throw the light on the process of high-speed ICT spread in randomly selected 50 countries between 1990 and 2015. For analytical purposes we chose only 50 economies in which the ICT penetration rates were the highest in 2015 according to the data provided by the World Telecommunications / ICT Indicators database 2016 (for the list of countries see Appendix 2). Our major research goal is to examine the emergence network effects with respect to 2 arbitrary selected core ICT indicators: Mobile cellular telephony (MCS hereafter) and Internet Users (IU hereafter). 
This paper is structured as follow. Introduction. Section 1 discusses the conceptual background providing theoretical foundations on the process of technology diffusion and emerging network externalities. Next, Section 2 presents the statistical data used in the research part and the methodological settings. Section 3 is entirely empirical, and finally Section 4 concludes.

\section{Network externalities and technology diffusion - theoretical standpoint}

Technology diffusion means expansion, spread, propagation, dissemination of all stock of human knowledge and inventions that simply represent all that embodied knowledge. Technology diffusion transfers information, knowledge and ideas over economies and societies regardless of their heterogeneity and complexity. Technology diffusion combines imitative and repetitive activities, but undeniably, these two are seminal for new technologies to become widespread, broadly accessed and used. Diffusion is rarely smooth and ordered process, but it is rather marked by uncertainty, especially visible in its early phases.

Undeniably, these are societal, economic and above all institutional factors which constitute a unique constellation of factors determining the speed of diffusion. As mentioned by Grübler (1991), new technologies do not diffuse into vacuum but interact with social, economic and institutional environment, depend on social attitudes toward risk taking and social capabilities to assimilate innovations. Considering the technology diffusion paths, three characteristic phases may be distinguished. In the begging, the process of diffusion is slow, and during the initial diffusion stage the number of new user of given technology remains negligible, thus relatively small share of society has an access to new technological solutions. During the early diffusion phase the number of contacts between adopters and non-adopter of new technology is still small, and thus the network growth is impeded due to high cost of adoption.

Obviously, the process of technology diffusion is effectively enhanced by multiple communication channels, therefore social networks and other communication systems play important role in this process. Rogers (1983) emphasizes the unique significance of interpersonal communication that he labeled 'the word-of-mouth' effect, and this special effect as well as the 'two-step communications' has been also stressed in works by Mansfield (1961 and 1971). David (1986) claims that the process of diffusion is less random when people buy new technologies enhanced by their potential profitability and belief that new technology is superior to the old one. In the same vein, Geroski (2000), Stoneman (2001) and Saviotti (2002) state that people do not make their decisions independently but are led by 'mass behavior' of all societies. All these determine the strength of the 'domino effect' that perpetuates the speed of new technologies dissemination society-wide. In similar vein, Peres et al. (2010) consider the process of propagation of new ideas and knowledge embodied in innovations as socially and economically driven and preconditioned, and second - even more important endogenously-led, which would mean that diffusion is mostly self-propagating process where the number of contacts between users and non-users is not restricted and may grow rapidly.

However, under favorable conditions, due to easiness of contacts and growing number of new-users, the 'domino effect' is revealed and hence the diffusion may speed up due to people`s positive attitudes towards new technology, significant cost reduction, or unveiling economies of scale. The number of new-users increases rapidly. Potentially, during the process of technology diffusion there may be exhibited some positive externalities (Loch and Huberman, 1999) that are defined as benefits generated by growing number of adopters and users of new technology (see also in Granovetter, 1978; Katz and Shapiro, 1985; Cusumano et $a l .$, 1992). In literature, the positive externalities are also recognized as the 'bandwagon effect' presenting the unique consumers` behavior associated with prestige-seeking. The emerging 
positive externalities phenomenon also suggests that growing number of users of new technology automatically increases its usefulness and encourages more people to adopt new technological solutions. Stoneman (1983), Markus (1987), Geroski (2000) or Peres et al. (2010) emphasize that emerging network externalities are the principal phenomenon that characterize technology diffusion and determine its dynamics. The network externalities are analogous to 'imitation effect' in the Bass model (see - Bass $(1969,1980)$ ), or the 'word-of-mouth' effect (or the 'domino effect') (see - Geroski, 2000, Lee et al., 2010). In other words, the value of new technological solution for an individual depends on how many people has already adopted it and use it, especially in communication technologies. Network externalities, which are intimately related to the process of technology diffusion and emerge as positive feedback from random contacts among economic agents, effectively enforce rapid growth of the network itself (Valente, 1996; Lechman, 2015). In other words, the network effects as positive re-alimentation schema generate sustainable multiplication of new users of given technology (Markus, 1987), and thus the number of new users usually starts to grow exponentially. Economides (1996) says that network externalities are kind of epidemics in social networks. Once the new technology is introduced to the market, it invades and spreads among the members of society like a contagious disease. Loch and Huberman (1999) underline that positive network effects encourage broader acceptance of new technology under uncertainty that is inherent in system of diffusion, and hence make people that imitate the behavior of others to repeat choices made by early adopters. Thereby, network effects demonstrate imitative effects, or imitative behavior, unveiled throughout the process of spread of new technologies. The positive feedback arises when the members of society tend to communicate among each other, and due to various communication channels a stock of knowledge on advantages and benefits of new technology is transmitted. In the studies of Cabral (1990) we find claims that network effects may enforce discontinuities along technology diffusion trajectory. Indeed, strong positive externalities unveiled during the process of technology diffusion often lead to sudden and unforeseeable 'catastrophe' in adoption of new technology; the demand explodes and the system passes from low-level equilibria to high-level equilibria. This 'catastrophe' enforces radical and permanent changes, and shifts the system from low-level trap. No need to say that socio-economic systems are characterized by unique inertia, which may heavily hinder rapid adoption of new technologies on the one hand, on the other hand it may lead to increases in uncertainty under people acts. Very often societies and its members need demand-side incentives to increase their propensity to acquire a new technology, which, in turn, is preconditioned by the intensity with which network effects positively affect the process of diffusion. Thereby, technology diffusion as a social phenomena is determined by unique combination of various prerequisites, encompassing both social aspects like social norms and attitudes and relative prices, willingness to pay for new technology, availability and relative utility of subsidiary and/or complementary goods and services, fundamental relationship between price and quality of newly offered technological solutions, or market regulations. In short, the dynamics of diffusion and its patterns is determined by social and economic elements, and the network externalities may effectively fuel this unique process.

\section{Materials and methods}

\subsection{Data and empirical sample}

In the empirical part we focus on examining the unique features of the process of ICT diffusion, and intend to unveil whether the spread of new technologies is subjected to the potentially emerging network effects (externalities), across selected 50 economies (see 
Appendix 2). We selected these countries regardless of their income per capita the only selection criteria was the mobile cellular telephony penetration rate reported in 2015 in World Telecommunications / ICT Indicators database 2016 - by convention we have chosen only 50 Top economies where MCS penetration was the highest. Henceforth, the remaining countryspecific characteristics (for instance, per capita income, education level, institutional quality or telecommunication market organization and level of competition) are not taken into account. By doing so, we wish to verify whether ICT diffusion may be claimed as endogenously driven process that is effectively enhanced by the emerging network effects among society members. The time span of the empirical analysis is subjected to availability of well-balanced time series of ICT data and thus it covers the period between 1990 and 2015. From the sample we have excluded not independent states - Macao and Hong Kong, as well as small island states - British Virgin Islands, Anguilla, Cayman Islands, Gibraltar, Antigua and Barbuda, Aruba (NL), ST. Kittis and Nevis. All statistical data on ICT are exclusively derived from World

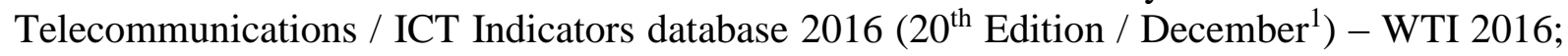
since all ICT data are based on common international standards, which ensures its cross-country comparability and consistency. For analytical purposed we have selected 2 core ICT indicators:

- Mobile Cellular telephone subscription per 100 inhabitants, which refers to the number of subscriptions to a public mobile-telephone service that provides an access to the PSTN (Public Switched Telephone Network) using cellular technology. The indicator includes (and is split into) the number of postpaid subscriptions; and the number of active prepaid accounts that have been used during the last three months. The indicator applies to all mobile-cellular subscriptions that offer voice communications (definition provided in WTI 2016);

- Internet Users as share of population, while this indicator can include both estimates and survey data corresponding to the proportion of individuals using the Internet based on results from national households surveys. The number should reflect the total population of the country; or at least individuals of 5 years and older. If this number is not available (i.e. target population reflects a more limited age group) an estimate for the entire population is produced (definition provided in WTI 2016).

In addition, we use data on price for 1-minute call (peak, on-net) indicating the prices on one-minute local call of a prepaid tariff made to the same mobile-cellular network during the peak time (these data are also extracted from from World Telecommunications / ICT Indicators database 2016); population density expresses the number of people per square kilometer of land area, and urbanization rate - proportion of country`s total population living in urban areas. All data on population density and urbanization are derived from World Development Indicators 2016 database. It is important to emphasize that country group selected to analysis is extremely diversified; selected countries share very few economic, social, institutional or political common features. The only characteristic that they share is very high rate of ICT adoption by society members.

\subsection{Research strategy}

Our research strategy combines a set of decriprive statistics that allow to unveil major characteristics of our data; density functions that we use to visualize changes in intesity of access to and use of ICT; locally weigthed polynomial smoother (LOWESS) adopted for nonparametric graphical approximation of the relationship between examined variables; and finally, panel and dynamic panel regresion that allow to verify the hypothesis on the emergence of the network effects along ICT diffusion trajectories.

\footnotetext{
${ }^{1}$ See - http://www.itu.int/en/ITU-D/Statistics/Pages/publications/wtid.aspx (accessed: January 2017).
} 
We use density curves that are plotted by adopting non-parametric estimation of the probability density function holding the form:

$$
f(x)=\frac{d}{d x} F(x)
$$

where $F(x)$ explains the continuous distribution of random variable $X$. The density curves that were generated by the kernel density estimator are continuous and show an 'empirical' distribution of variables. To estimate density $\mathrm{f}(\mathrm{x})$, we use its discrete derivative, and so the kernel estimator takes a general form:

$$
f^{\prime}(x)=\frac{1}{n h} \sum_{i=1}^{n} k\left(\frac{X_{i}-x}{h}\right)
$$

where $k(u)$ is a kernel function that satisfies $\int_{-\infty}^{\infty} k(u) d u=1$. In our case $f^{\prime}(x)$ shows the percentage of observations located near $x$. If many observations are located near $x$, then $f^{\prime}(x)$ is large, and the opposite otherwise.

Locally weighted polynomial smoother is a nonparametric method used to graphically fit the curve displaying relationship between two variables. This method of analysis is useful and widely adopted as it allows to relax rigid assumptions of conventional parametric analysis and regressions, and thus no assumption regarding the form of the relations is made. A huge advantage of using the LOWESS method is that it is outlier resistant and thus no disturbances in results are introduced.

Following Cleveland (1979) we approximate the function having a general form:

$$
f(.)
$$

under assumption that all errors $e_{i}$ generated by the model are identically zero. Having defined $x_{i}$ as one of the covariates we can estimates the $f($.$) by using the multivariate polynomial form$ where respective $x_{i}$ is chosen to extrapolate:

$$
y_{i}=f\left(x_{i}^{*}\right)
$$

if $i=1, \ldots \ldots k$, in the $k$-nearest neighborhood of $x^{*}$, with underlying assumption that $f$ is the locally a smooth function.

Finally, to examine the statistical associations between changing Mobile-cellular telephony penetration rates (MCS) and number of individuals using Internet network (IU), we use panel regression analysis. With this aim we build separate panels - for Mobile-cellular telephony and Internet users to examine the hypothesized relationships. The mobile cellular telephony and Internet user penetration rates are denoted as response variables; while as predictors we consider all of the variables considered in the preceding section. By doing so, we aim to infer about the intensity of the influence of selected factors on MCS and IU in countries in scope.

In our research we rely on the fixed effects regression, which allows heterogeneity across countries, we estimate the Eq. (5):

$$
Y_{i, y}=\alpha+\beta\left(\dot{x}_{i, y}^{\prime}\right)+u_{i, y}
$$

where $\boldsymbol{\alpha}$ is the scalar, $\boldsymbol{Y}_{\boldsymbol{i}, \boldsymbol{y}}$ denotes alternatively $\mathrm{MCS}_{\mathrm{i}, \mathrm{y}}$ or $\mathrm{IU}_{\mathrm{i}, \mathrm{y}} ; \boldsymbol{\beta}$ is the $\boldsymbol{L} \times \mathbf{1}$ and $\boldsymbol{x}_{\boldsymbol{i}, \boldsymbol{y}}$ stands for the $\boldsymbol{i} \boldsymbol{y}$ th observation on $\boldsymbol{L}$ explanatory variables (Baltagi, 2008). The subscripts $\boldsymbol{i}$ and $\boldsymbol{y}$ 
stand for country and time accordingly. In Eq.(5), the $\boldsymbol{u}_{i, y}=\boldsymbol{\mu}_{\boldsymbol{i}}+\boldsymbol{v}_{\boldsymbol{i}, \boldsymbol{y}}$, while the $\boldsymbol{\mu}_{\boldsymbol{i}}$ accounts for the unobservable and time-invariant country-specific effect, which are not captured in the model, and the $\boldsymbol{v}_{\boldsymbol{i}, \boldsymbol{y}}$ is the reminder disturbance (the observation-specific errors) (Greene, 2003; Baltagi, 2008). To control possibly emerging heteroskedasticity or within-panel serial correlations, robust standard errors are specified and reported (Arellano, 1987). In addition, to investigate the potential importance of emerging network effects for current ICT deployment and usage we use dynamic panel regression approach (Arellano and Bond, 1991). We specify the dynamic panel as follows:

$$
\boldsymbol{Y}_{i, y}=\psi\left(\boldsymbol{Y}_{i, y-1}\right)+\boldsymbol{\beta}\left(\grave{\boldsymbol{x}_{i, y}}\right)+\boldsymbol{u}_{i, y}
$$

where $\boldsymbol{Y}_{\boldsymbol{i}, \boldsymbol{y}-\mathbf{1}}$ shows the lagged value of $\mathrm{MCS}_{\mathrm{i}, \mathrm{y}}$ or $\mathrm{IU}_{\mathrm{i}, \mathrm{y}}$, the $\psi$ and $\xi$ stand for $\boldsymbol{Y}_{\boldsymbol{i}, \boldsymbol{y}-\mathbf{1}}$ coefficient respectively, and the remaining notations are as in Eq.(5). For the model specified in Eq.(6), we assume the $\boldsymbol{u}_{i, y}=\boldsymbol{\mu}_{\boldsymbol{i}}+\boldsymbol{v}_{\boldsymbol{i}, \boldsymbol{y}}$, if $\boldsymbol{\mu}_{\boldsymbol{i}} \sim \boldsymbol{I I D}\left(\mathbf{0}, \boldsymbol{\sigma}_{\boldsymbol{\mu}}^{2}\right)$ and $\boldsymbol{v}_{\boldsymbol{i}, \boldsymbol{y}} \sim \boldsymbol{I I D}\left(\mathbf{0}, \boldsymbol{\sigma}_{\boldsymbol{v}}^{\mathbf{2}}\right)$ (Baltagi, 2008). Analogously to the fixed effects regression, we estimate the Eq.(X) using robust standard errors to get the errors consistent with panel-specific autocorrelations and heteroskedasticity. As Sargan test of over-identifying restrictions is not available after robust estimations, we adopt the Arellano-Bond test for second-order autocorrelation in the first-differenced errors (Arellano and Bond, 1991).

To check for network effects, we specify our empirical models as follows:

$$
M C S_{t, i}=\alpha+\beta M C S_{t-1, i}+\delta \operatorname{call}_{t, i}+\delta^{\prime}\left[\operatorname{call}_{t, i}\right]^{2}+\mu p o p_{t, i}+\vartheta u r b_{t, i}+\varepsilon_{t, i},
$$

And

$$
I U_{t, i}=\alpha+\beta I U_{t-1, i}+\delta \operatorname{charg} e_{t, i}+\delta^{\prime}\left[\operatorname{charge}_{t, i}\right]^{2}+\mu p o p_{t, i}+\vartheta u r b_{t, i}+\varepsilon_{t, i},
$$

where $M C S_{t, i}$ stands for mobile cellular penetration rate in $t$-time and $i$-country, $I U_{t, i}$ - Internet penetration rate, $M C S_{t-1, i}$ and $I U_{t-1, i}$ are their lagged values. Next, call $_{t, i}$ is the price of 1minute call, $\delta$ charge $e_{t, i}$ is the monthly fixed-broadband charge, $\operatorname{pop}_{t, i}$ - population density, and $u r b_{t, i}$ is the urbanization rate.

Hereinafter we claim that the process of diffusion of mobile cellular telephony may be heavily determined by the emerging network effects that are unveiled due to multiple interpersonal contacts. In this case we expect to uncover the existence of strong network effects that may be demonstrated as result of three different factors; first - the level of ICT adoption in previous periods, second - urbanization rate, and third - population density. All these elements may positively affect growth of new users of new technology mainly due to multiple contacts among users and non-users, when the 'domino effects' are unveiled. In addition we include another variable in our panel analysis approximating cost of access to and use ICT, namely: price of 1-minute call (for mobile cellular telephony) and monthly fixed-broadband subscription charge (for Internet users). Potentially costs of access to and use of new technology shall strongly determine ICT penetration rates and thus we treat them as control variables in this research.

In what follows we present the results of our research. In the first step we show and discuss descriptive statistics on ICT diffusion across selected 50 countries between 1990 and 2015. In this part our descriptive evidence is enriched by graphical representation of changes in this respect. Next, we demonstrate the results of panel regression analysis results, which aimed to verify what determines ICT diffusion across countries in scope. With this aim we have 
included in our panel models specification, a bundle of variables (see Sect. 2.1) that hypothetically may affect the process of ICT dissemination, and to unveil the existence of the network externalities. To verify the latter we use fixed and dynamic panel models.

\section{Empirical findings}

\subsection{Descriptive and graphical evidence}

This section is aimed to shed light on the process of ICT diffusion in selected 50 countries observed for the last 26 years (between 1990 and 2015). This part shows that the process of spread of new information and communication technologies is phenomenally rapid across all examined economies regardless of their internal specific features. It is also designed to demonstrate several striking facts about ICT diffusion across countries in scope, and puts special emphasis on drawing a general picture of key ICT diffusion trends. Table 1 summarizes the ICT indicators (Mobile cellular telephony and Internet users) descriptive statistics for the period 1990 and 2015. This picture is additionally supported by graphical evidence displayed in Fig. 1 in Appendix 1 demonstrating ICT diffusion trajectories with regard to examined ICT indicators. The results provided in Table 1 and in Fig. 1 in Appendix 1 demonstrate how fast and disruptive were changes in access to and use of ICT in selected economies during analyzed period. Taking a closer look at MCS and IU diffusion paths for selected countries (see - Fig. 1 in Appendix 1) several striking similarities are easily observable. Regarding mobile cellular telephony diffusion paths, three characteristic phases along diffusion patterns may be distinguished; these are early (initial) diffusion stage during which the rate of diffusion is low and the growth in ICT penetration rate is slow. Next, somewhere around 1996-1997 we observe the specific take-off into exponential growth, thus the stage of rapid diffusion is achieved and during this stage we note rapid growth of number of users of mobile cellular telephony. Finally, we observe counties entering stabilization (saturation) phase, somewhere around the period 2010-2012, when the rate of diffusion slows down. In fact, analogous observations can be made regarding Internet users diffusion curves, which speaks in support of the hypothesis that the intime dynamics of spread of both ICT tools across society members, as well as their diffusion time-paths are very similar. Moreover, when taking a closer look at the graphs displaying the annual dynamics of mobile cellular telephony growing deployment rates and Internet users penetration rates (see right-hand graphs), we note that during the early diffusion phase the yearto-year growth dynamics is extremely high and the process of diffusion is speeding up, which inevitably leads to rapidly increasing ICT penetration rates. The latter is undeniably the direct consequence of strong network effects unveiled when new-users (innovators) adopt new technological solutions and this - due to the 'word of mount effect', enhances more society members to buy them. As a result, the total number of users of new technology is growing and so ICT penetration rates do. Obviously, as the process of technology diffusion proceeds, the annual growth rates diminish, finally - during the stabilization (saturation) phase, they approach zero. 
Table 1. Mobile cellular telephony and Internet penetration rates. 1990-2015

\begin{tabular}{|c|c|c|c|c|c|c|c|c|c|}
\hline & Year & $\begin{array}{l}\text { \# of } \\
\text { obs. }\end{array}$ & Mean & $\begin{array}{l}\text { Std. } \\
\text { dev. }\end{array}$ & Min.value & Max.value & $\begin{array}{l}\text { Coefficient } \\
\text { of variation }\end{array}$ & $\begin{array}{l}\text { Gini } \\
\text { Index }\end{array}$ & $\begin{array}{l}\text { Atkinson } \\
\text { index } \\
\text { (for } \\
\varepsilon=0.5 \text { ) } \\
\end{array}$ \\
\hline \multirow{3}{*}{$\begin{array}{l}\text { Mobile } \\
\text { cellular } \\
\text { telephony }\end{array}$} & 1990 & 24 & 0,96 & 1,45 & $\begin{array}{c}0,01 \\
\text { [Indonesia] }\end{array}$ & $\begin{array}{c}5,4 \\
\text { [Sweden] }\end{array}$ & 1,47 & 0,65 & 0,38 \\
\hline & 2000 & 49 & 22,4 & 24,8 & $\begin{array}{c}0,10 \\
{[\text { Mali] }}\end{array}$ & $\begin{array}{c}76,3 \\
\text { [Austria] }\end{array}$ & 1,09 & 0,57 & 0,30 \\
\hline & 2015 & 50 & 152,9 & 21,9 & $\begin{array}{c}125,8 \\
\text { [Thailand] }\end{array}$ & $\begin{array}{c}231,7 \\
\text { [Kuwait] }\end{array}$ & 0,14 & 0,07 & 0,004 \\
\hline \multirow{3}{*}{$\begin{array}{l}\text { Internet } \\
\text { penetration }\end{array}$} & 1990 & 7 & 0,34 & 0,25 & $\begin{array}{c}0,02 \\
{[\text { Italy] }}\end{array}$ & $\begin{array}{c}0,59 \\
\text { [Switzerland] }\end{array}$ & 0,68 & 0,37 & 0,16 \\
\hline & 2000 & 49 & 10,9 & 13,6 & $\begin{array}{c}0,05 \\
\text { [Cambodia] }\end{array}$ & $\begin{array}{c}47,1 \\
\text { [Switzerland] }\end{array}$ & 1,22 & 0,61 & 0,33 \\
\hline & 2015 & 50 & 59,3 & 24,8 & $\begin{array}{c}10,3 \\
{[\text { Mali] }}\end{array}$ & $\begin{array}{c}97,3 \\
\text { [Luxembourg] }\end{array}$ & 0,41 & 0,23 & 0,05 \\
\hline
\end{tabular}

Source: Author`s calculations using STATA 14 software.

As for the examined economies, during the period 1990 and 2015, the process of diffusion of mobile cellular telephony is reported as astonishingly high. Looking at density curves (see Fig. 1 in Appendix 1, left-hand graphs) drawn for MCS penetration rates for the years 1990, 2000 and 2015 respectively, we observe drastic shifts in adoption and usage of mobile cellular telephony both in terms of absolute country-wise penetration rates and in terms of changing cross-country inequalities. The shape of MCS density curve plotted for 1990 suggests one-peak distribution with long right tail; and the highest density is observed for very low penetration rates (between 0 and 2 per 100 inhab.). It shows that in the initial year the adoption of mobile cellular telephony in examined economies was negligible. In 2000, the overall picture has slightly changed showing increasing MCS penetration rates; the MCS density curve reshaped and the twin-peak line emerged suggesting temporal formation of two distinct country groups having radically different MCS penetration rates. The first group encompassed those countries where in 2000 the mobile cellular telephony adoption was still relatively low; while the second - where this type of ICT has already been relatively well diffused across society members. The second group of economies was much less numerous. Finally, in 2015, the twin-peak shape of density curve disappeared and the one-peak appeared with short right tail, showing that examined group of countries became relatively homogenous in terms of MCS adoption. Moreover, we see that in 2015 the 'flow' of the density curve shows that even in the worst performing country the MCS penetration rate was higher than 100 per 100 inhabitants, the 'average' MCS penetration was somewhat about 150 per 100 inhabitants (sic!), while there still was a group of economies enjoying MCS penetration rates above 200 per 100 inhabitants. This picture is supported by numerical evidence provided in Table 1 including elementary descriptive statistics. In 1990, due to limited data availability, our calculations are only for 24 economies. Initially, the average mobile cellular telephony penetration rate was just 0,96 per 100 inhab.; while the minimum value was for Indonesia $(0,01)$ and the maximum for Sweden $(5,4)$, which shows that the overall adoption of mobile telephony was negligible during that year. Additionally calculated coefficient of variation, Gini and Atkinson indices suggest relatively high cross-country inequalities in this respect. However, during the next 25 years the overall picture dramatically changed. According to our calculations the average annual rate of growth of MCS penetration rate was at around 19,5\% per annum. 
Due to rapid shifts in mobile cellular telephony adoption observed in each of examined countries, the average MCS penetration rate increased up to 152,9 per 100 inhabitants, and this astonishing growth was accompanies by radical drops in cross-country inequalities in terms of access to and use of mobile telephony. Note that in 2015 coefficient of variation, Gini index and Atkinson index were 0,14, 0,07 and 0,004 respectively, and thus we may claim that crossnational inequalities almost disappeared with this regard. Taking a closer look at changes reported in terms of growing Internet usage, we observe insignificantly weaker dynamic of this process, despite we claim that shifts in growing access to Internet network were marked by some specific changes. To show these shifts we have additionally plotted density curve for the year 1995 (see Fig. 1 in Appendix 1). Note that between the period 1990 and 1995 radical changes in general overview are observed. In 1990 all examined economies were 'equally poor' in terms of access to and use of Internet network; the state of its development was negligible.

However, during the next 5 years the picture changed, which is clearly demonstrated by the IU density curve for 1995 . The IU density line for 1995 is highly asymmetric; it is a onepeak distribution with very long right tail, showing the existence of two different groups of countries. The first group where the state of Internet network development remained, to a large extend, unchanged from 1990; and the second is a group of countries that forged ahead but still huge disparities emerged among them. Next, in 2000, we still observe the one-peak distribution including right tail; and only in 2015 the change is radical and visually resembles the picture drawn for 1990, but for significantly higher IU penetration rates. Descriptive statistics provided in Table 1, tell us more about the basic characteristics of the process of Internet network diffusion within examined country group. Obviously, in 1990 (note that calculations are only for 7 economies) the average IU penetration rate was very low; the highest IU penetration rates was observed for Switzerland - IU=0,59\%. In 2015, the average Internet penetration rate resulted to be almost $60 \%$, reaching the highest level in Luxembourg $(97,3 \%)$ and the lowest in Mali (10,3\%). Similarly to what was demonstrated in case of mobile cellular telephony, during the period 1990 and 2015 radical fall in cross country inequalities are demonstrated in case of changing IU penetration rates (compare coefficients of variation, Gini and Atkinson indices for respective years). These falling cross-country disparities visible both for mobile cellular telephony and for Internet network speak in support of our initial hypothesis on emerging network effects that endogenously drive ICT diffusion. At the beginning of the period of analysis, all the countries were equally 'ICT-poor' but then due to the dynamic spread of new technological solutions they were gradually becoming 'ICT-rich'. The graphical evidence, together with descriptive and inequality statistics summarized in Table 1, helps to realize how pervasively new information and communication technologies were expanding across our selected economies between 1990 and 2015. Furthermore, it helps to understand that between 1990 and 2015 the cross-national distribution of ICT was becoming more and more equalized.

\subsection{Network effects identification}

As pictured in Sect. 3.1, during the period 1990-2015 all 50 examined economies have experienced extraordinary rapid diffusion of information and communication technologies. Major changes have been observed, not only in terms of access to mobile-cellular telephony, but also in regard to growing accessibility of Internet networks. These undeniably positive changes allowing countries to forge ahead in terms of technological advancements have been subjected to multiple aspects. Thus, our continuing efforts are directed towards unveiling the existence and the strength of potentially arising network effects, which enforce a fast spread of new technologies, and identifying other factors that hypothetically might have positively contributed to the process of ICT diffusion across countries in scope. With these aims we have arbitrary selected additional 3 elements (see Sect. 1) that may help us to explain a rapid growth 
in access to and use of mobile cellular telephony and Internet network. To examine the statistical associations between changing Mobile-cellular telephony penetration rates (MCS) and number of individuals using Internet network (IU), we use panel regression analysis. With this aim we construct two separate panels - for Mobile-cellular telephony and Internet users to unveil the hypothesized relationships. The mobile cellular telephony $\left(\mathrm{MCS}_{\mathrm{i}, \mathrm{y}}\right)$ and Internet user $\left(\mathrm{IU}_{\mathrm{i}, \mathrm{y}}\right)$ penetration rates are denoted as response variables; while as predictors we consider the following: lagged values of response variables, price of 1-minute call, lagged price of 1-minute call, fixed-broadband subscription charge, lagged fixed-broadband subscription charge, population density and urbanization rates. Further we argue that the process of diffusion of mobile cellular telephony and growth of usage of Internet network may be enhanced by dropping costs of access and usage this form of communication tool, but also it might be affected by population density and urbanization rate, which facilitate interpersonal contacts and thus positively contribute to the emergence of network effects. Arguably, the network effects may be demonstrated as result of three different elements: the level of ICT adoption in previous periods, urbanization rate, and population density. All these factors may positively affect growth of new users of mobile-cellular telephony mainly due to multiple contacts among users and non-users, when the 'domino effects' are unveiled. Factors like population density and urbanization rate may be decisive for enabling the emergence of the network effects, which, in turn, enforces rapid growth of new users of technology. As briefly explained in Sect. 1, the network effect emerges as the population of hypothetical agents tends to acquire new technologies immediately after their introduction to the telecommunication market. Initially, the groups of 'users' and 'non-users' coexist, but due to the word-of-mount effect the 'nonusers' imitate those who already use new technologies, and so they are gradually 'contaminated' by new technologies. The 'contamination effect' arises when agents are involved in personal contacts, and this perpetuates the process of technology propagation. We assume that the probability of 'contamination' is time invariant and 'non-users' convert into 'users' immediately once the two get in touch. Henceforth, this process may be effectively facilitated in densely populated areas where the probability of frequent interpersonal contact is high. These interpersonal contacts are perceived as significant driving forces of diffusion processes, which inevitably leads to a growing number of 'users' of new technology. Undoubtedly, ICT are, above all, network technologies; they are the network itself, they generate new networks and diffuse due to the network externalities, and thus diffusion of ICT should be hypothetically highly facilitated in advantageous (high urbanized and densely populated) countries.

Further, we present and discuss the results of the empirical analysis. Figures 2 and 3 display graphically the relationship between MCS and IU, and their selected determinants. Next Tables 2 and 3 summarize panel regression estimates. 
Mobile cellular telephony determinants
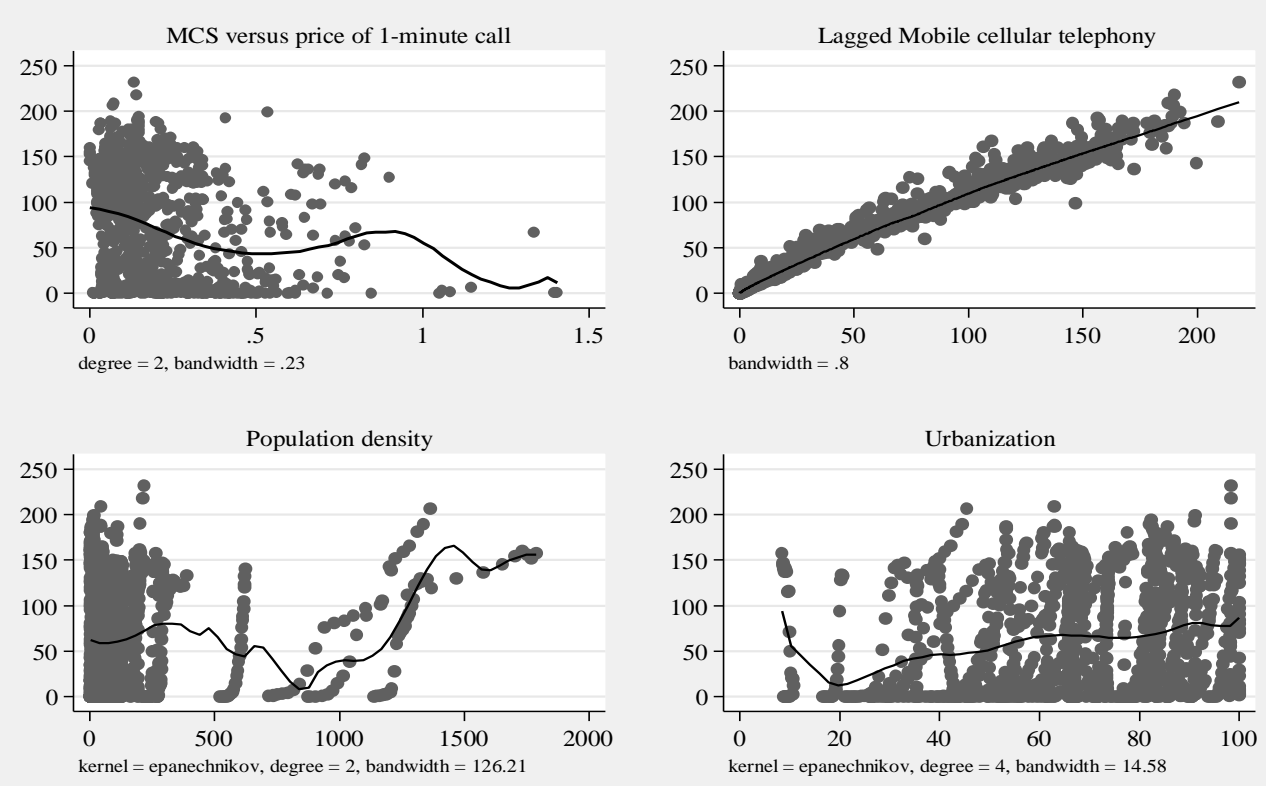

Note: Singapore - excluded; on vertical axis - mobile cellular telephony penetration rates.

Fig. 2. Mobile cellular telephony versus selected determinants. 1990-2016 Source: Author`s elaboration using STATA 14 software.

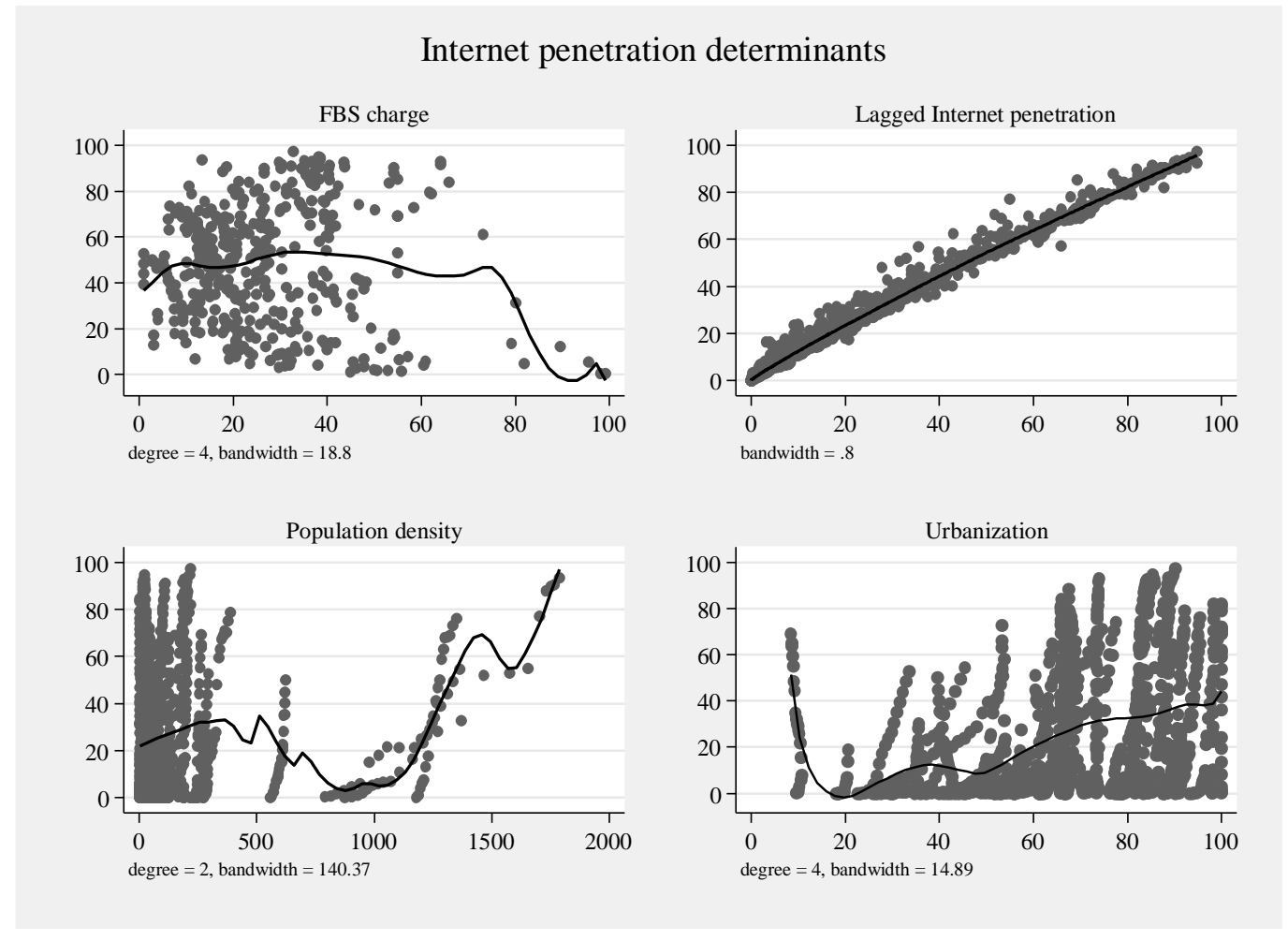

Note: Singapore - excluded; FBS charge - fixed-broadband subscription charge; on vertical axis - Internet penetration rates.

Fig. 3. Internet users versus selected determinants. 1990-2016

Source: Author`s elaboration using STATA 14 software. 
Table 2. Mobile cellular telephony determinants and Network Effects. 1990-2015. Panel regression results

\begin{tabular}{|c|c|c|c|c|c|c|c|}
\hline LnMCS & & & & & & & \\
\hline & $\mathrm{FE}(1)$ & $\mathrm{FE}(2)$ & $\mathrm{FE}(3)$ & $\mathrm{FE}(4)$ & $\mathrm{FE}(5)$ & $\mathrm{DP}(1)$ & $\mathrm{DP}(2)$ \\
\hline LnMCS laoged & & & & & & 0,89 & 0,89 \\
\hline LnMics_lagged & & & & & & {$[0,03]$} & {$[0,03]$} \\
\hline & $-1,18$ & & & $-0,63$ & $-2,50$ & 0,08 & $-0,13$ \\
\hline Lncall & {$[0,11]$} & & & {$[0,08]$} & {$[0,24]$} & {$[0,06]$} & {$[0,09]$} \\
\hline$(\mathrm{InCall1})^{2}$ & & & & & $-0,45$ & & $-0,05$ \\
\hline$(\text { Lncall })^{-}$ & & & & & {$[0,05]$} & & {$[0,03]$} \\
\hline & & 7,76 & & 4,01 & 3,83 & 0,15 & 0,21 \\
\hline LnPop & & {$[0,37]$} & & {$[0,32]$} & {$[0,31]$} & {$[0,27]$} & {$[0,28]$} \\
\hline JnUrb & & & 21,8 & 12,9 & 13,2 & 0,71 & 0,79 \\
\hline Lnuro & & & {$[0,88]$} & {$[0,85]$} & {$[0,82]$} & {$[0,74]$} & {$[0,73]$} \\
\hline r-sq. (within) & 0,11 & 0,28 & 0,35 & 0,49 & 0,52 & & \\
\hline Mean VIF & & & & 1,02 & 6,43 & & \\
\hline \# of obs. & 913 & 1158 & 1191 & 891 & 891 & 756 & 756 \\
\hline \# of instruments & & & & & & 277 & 278 \\
\hline & 116,7 & 448,7 & 615,0 & 267,5 & 232,8 & & \\
\hline $\mathrm{F}$ test $(\operatorname{Prob}>\mathrm{F})$ & {$[0,00]$} & {$[0,00]$} & {$[0,00]$} & {$[0,00]$} & {$[0,00]$} & & \\
\hline$\chi^{2}\left(\operatorname{Prob}>\gamma^{2}\right)$ & & & & & & 2645,0 & 2347,0 \\
\hline$\chi(15100=\chi)$ & & & & & & {$[0,00]$} & {$[0,00]$} \\
\hline Rho & 0,25 & 0,97 & 0,95 & 0,96 & 0,97 & & \\
\hline $\begin{array}{l}\text { AR test }\left(2^{\text {nd }}\right. \\
\text { order }) \text { Prob }>z\end{array}$ & & & & & & $\begin{array}{l}-1,54 \\
{[0,13]}\end{array}$ & $\begin{array}{l}-1,45 \\
{[0,15]}\end{array}$ \\
\hline
\end{tabular}

Note: for fixed-effects estimation - standard errors reported; for dynamic panel estimations - robust standard errors reported; constant included - not reported; in italics - coefficients statistically insignificant; Singapore - excluded.

Source: Author`s estimates using STATA 14 software.

Table 3. Internet penetration determinants and Network Effects. 1990-2015. Panel regression results

\begin{tabular}{|c|c|c|c|c|c|c|c|}
\hline LnIU & & & & & & & \\
\hline & $\mathrm{FE}(1)$ & $\mathrm{FE}(2)$ & $\mathrm{FE}(3)$ & $\mathrm{FE}(4)$ & $\mathrm{FE}(5)$ & $\mathrm{DP}(1)$ & $\mathrm{DP}(2)$ \\
\hline 1 & 2 & 3 & 4 & 5 & 6 & 7 & 8 \\
\hline LnIU_lagged & & & & & & $\begin{array}{c}0,82 \\
{[0,02]}\end{array}$ & $\begin{array}{c}0,81 \\
{[0,04]}\end{array}$ \\
\hline LnFBS_charge & $\begin{array}{c}-0,51 \\
{[0,04]}\end{array}$ & & & $\begin{array}{c}-0,37 \\
{[0,03]}\end{array}$ & $\begin{array}{c}-0,13 \\
{[0,04]}\end{array}$ & & $\begin{array}{c}-0,03 \\
{[0,03]}\end{array}$ \\
\hline$(\text { LnFBS_charge })^{2}$ & & & & & $\begin{array}{c}-0,04 \\
{[0,00]}\end{array}$ & & \\
\hline LnPop & & $\begin{array}{c}7,56 \\
{[0,38]}\end{array}$ & & $\begin{array}{c}2,84 \\
{[0,29]}\end{array}$ & $\begin{array}{c}2,21 \\
{[0,32]}\end{array}$ & $\begin{array}{c}0,25 \\
{[0,14]}\end{array}$ & $\begin{array}{c}0,05 \\
{[0,17]}\end{array}$ \\
\hline LnUrb & & & $\begin{array}{c}19,7 \\
{[0,91]}\end{array}$ & $\begin{array}{c}3,88 \\
{[0,71]}\end{array}$ & $\begin{array}{c}4,54 \\
{[0,74]}\end{array}$ & $\begin{array}{c}0,03 \\
{[0,44]}\end{array}$ & $\begin{array}{c}1,24 \\
{[0,44]} \\
\end{array}$ \\
\hline r-sq. (within) & 0,29 & 0,28 & 0,31 & 0,54 & 0,57 & & \\
\hline Mean VIF & & & & 1,05 & 2,30 & & \\
\hline \# of obs. & 414 & 1064 & 1096 & 406 & 336 & 964 & 332 \\
\hline \# of instruments & & & & & & 303 & 166 \\
\hline $\mathrm{F}$ test $($ Prob $>F)$ & $\begin{array}{l}148,8 \\
{[0,00]}\end{array}$ & $\begin{array}{c}396,6 \\
{[0,00]}\end{array}$ & $\begin{array}{l}466,0 \\
{[0,00]}\end{array}$ & $\begin{array}{c}141,3 \\
{[0,00]}\end{array}$ & $\begin{array}{c}94,7 \\
{[0,00]}\end{array}$ & & \\
\hline$\chi^{2}\left(\operatorname{Prob}>\chi^{2}\right)$ & & & & & & $\begin{array}{c}7455,2 \\
{[0,00]}\end{array}$ & $\begin{array}{l}1328,0 \\
{[0,00]}\end{array}$ \\
\hline
\end{tabular}




\begin{tabular}{lccccccc}
\hline \multicolumn{1}{c}{1} & 2 & 3 & 4 & 5 & 6 & 7 & 8 \\
\hline Rho & 0,84 & 0,97 & 0,95 & 0,99 & 0,99 & & \\
\hline $\begin{array}{l}\text { AR test }\left(2^{\text {nd }} \text { order) }\right. \\
\text { Prob }>\mathrm{z}\end{array}$ & & & & & & 0,41 & $-1,05$ \\
\end{tabular}

Note: for fixed-effects estimation - standard errors reported; for dynamic panel estimations - robust standard errors reported; constant included - not reported; in italics - coefficients statistically insignificant; Singapore - excluded. Source: Author`s estimates using STATA 14 software.

Visual inspection of empirical findings demonstrated on Figs. 2 and 3 suggests that several regularities may be identified. Regarding the relationship between mobile cellular telephony and its selected determinants, we see that it is negatively correlated with price of 1minute call. In this case calculated correlation coefficient resulted to be $(-0,23)$ (see also correlation matrix in Appendix 2). The case-specific graph (left-side up graph in Fig. 2) shows that a huge majority of observations fall between zero and 0,5 USD price of 1-minute call (higher prices are only incidental) regardless of the achieved MCS penetration rate, which hypothetically would mean that price of 1-minute call is not a strong determinant of the usage of the mobile cellular telephony. These evidence might suggest that there is no strong relationship between changing mobile-cellular telephony penetration rates and prices of this form of communication, but increasing deployment of mobile telephony is rather subjected to other factors that enhance its rapid diffusion. The latter is probably due to the fact that people`s propensity towards adopting technological novelties is predominantly driven by the factors other than price as long as they can afford it. Similar observation can be made with respect to the relationship between Internet penetration rates and the cost of using Internet network approximated by fixed-broadband monthly subscription charge (see Fig. 3, left-side up graph). In this case observations are relatively scattered and do not demonstrate any defined regularity. The calculated correlation coefficient is 0,15 (see - Appendix 2) suggesting positive but statistically insignificant relationship. In this case we also might argue that neither in case of mobile cellular telephony adoption nor in case of Internet usage the prices of access and usage are the major determinants of achieved penetration rates. Brief graphical analysis of the relationship between both MCS and IU versus population density suggests lack of regularities with this respect. However, one shall borne in mind that variables such as population density are relatively time invariant; their changes are slow especially in highly developed countries. Analogous observations are valid when examining graphically the relationship between MCS and IU and urbanization rates. Visually the statistical association between MCS and IU versus urbanization rate is demonstrated through the LOWESS line located horizontally, which indicates very weak statistical association between examined variables. Despite the fact that urbanization rates change spasmodically in high-income economies, in developing countries its shifts are more dynamic, its rate of change is significantly lower than observed between 1990 and 2015 speed of ICT adoption. This preliminary evidence on ICT adoption versus population density and urbanization rate interdependency confirms at least partially that across the examined economies these factors are positively related. Finally we have examined the statistical relationship between ICT penetration rate and its lagged values. Both in case of mobile cellular telephony and Internet penetration rate we observe strong associations between examined variables, which might preliminary speak in support of our hypothesis that ICT diffusion is effectively driven by endogenously emerging network effects. Calculated correlation coefficients are 0,98 and 0,99 for mobile cellular telephony and Internet adoption respectively. This graphical evidence shows that ICT adoption rate in previous year drives growth of ICT penetration in consecutive years, which demonstrates that interpersonal contacts enhance new-users do acquire new technological solutions. The 'domino effects' are unveiled. This visual inspection of the relationships between two selected ICT indicators and their 
potential determinants is enriched by the panel regression analysis, which results are summarized in Tables 2 and 3. First, one shall be borne in mind that number of observation varies among estimated panel models, and this fully subjected to different data availability regarding explanatory variables used in consecutive specifications. Note that available time series for fixed-broadband charge (FBS_charge) suffer from significant breaks, so models where this variable is included are estimated for significantly fewer observations (see, e.g. $\mathrm{FE}(1), \mathrm{FE}(4), \mathrm{FE}(5)$ and $\mathrm{DP}(2)$ for Internet penetration determinants in Table 3). tt is important to note that different number of observation affects the results of the analysis; thus shall be borne in mind when drawing conclusions and recommendations. Table 2 displays outcomes of panel regression results for fixed effects models and dynamic panel models, regarding mobile cellular telephony diffusion determinants. We hypothesize that MCS growing adoption rates have been effectively enhanced decreasing costs of usage, but also spread of this form of telecommunication has been fostered in densely populated regions, in urban areas and above all, it is facilitated by the network externalities that unveil due to growing number of random contacts among society members. In our case, we control the network effect by estimating the dynamic panel models including 1-year lagged value of MCS. As initially claimed, our results confirm that costs of access to and use of mobile cellular telephony condition its society-wide adoption. Consecutive estimates of models FE(1), FE(4) and FE(5) demonstrate existence of statistically significant negative association between MCS and prices of 1-minute call despite the fact that the differences in values of respective coefficients differ significantly - see, for instance, $(-0,63)$ in $\mathrm{FE}(4)$ and $(-2,5)$ in $\mathrm{FE}(5)$. However, it is interesting that the model $\mathrm{FE}(1)$ where price of 1-minute call is the only explanatory variable has the weakest explanatory power as its r-square is only 0,11 . The latter might suggest that although prices of access to and use of mobile cellular telephony are important driver of its growing adoption among society members, probably its explanatory power is relatively weak compared to other elements. It may also show extremely high people`s propensity towards acquiring new and advantageous technological solution, which they wish to buy regardless of the price. As expected when introducing to the model population density as the only explanatory variable MCS penetration rate growth is effectively enhanced in densely populated areas. Regarding the urbanization rate introduced to the model - see FE(3), as explanatory variables, give qualitatively similar results. In FE(3) estimated coefficient that the regressor holds is positive, high and statistically significant, which - as in the previous case, shows that in urbanized areas new technologies may diffuse relatively faster and this process is highly facilitated. Next two models - FE(4) and $\mathrm{FE}(5)$ are estimated for all 3 explanatory variables. Following the r-square we see that the model FE(5) holds the 'best' explanatory power - r-sq=0,52 for 891 observations; although the model $\mathrm{FE}(4)$ is insignificantly 'worse' in this regard. In FE(5) all the estimated coefficients standing by each explanatory variable hold the expected sign and are statistically significant. The highest value of coefficient is reported for variable - urbanization rate, which again confirms important role of interpersonal contacts in technology spreading. Finally we have tested dynamic panel models - DP(1) and DP(2), with lagged MCS variable included. Both DP(1) and DP(2) are estimated for 756 observations, with 277 for $\mathrm{DP}(1)$ and 278 for $\mathrm{DP}(2)$ instruments used. In both cases the estimated coefficients for respective explanatory variable are very similar. Notably, both for DP(1) and DP(2) the MCS_lagged variable holds the same coefficient - 0,89, and this result-is statistically significant. Surprisingly, the remaining estimated coefficients standing by variables: prices of 1-minute call, population density and urbanization rate resulted to be statistically insignificant. The latter shows that once MCS_lagged variable is introduced to the model it captures all of the model variability and so all the other regressors lose their power in explaining changes in MCS diffusion. Arguably, we might claim that these estimations outcome again confirm our initial supposition that ICT diffusion is the process endogenously driven and that emerging network externalities play a dominant role in enhancing growing adoption of new 
information and communication technologies. Table 3 summarizes analogues estimates for Internet penetration rates. Also in this case we subject Internet usage to prices of access - in here approximated by fixed-broadband subscription charge, population density and urbanization rates. Finally, we add IU_lagged variable and estimate dynamic panel models to capture the network effects. With regard to Internet penetration rates determinants, our major findings coincide with our estimates for mobile cellular telephony diffusion. In this case we also find that the variable explaining costs of access to and use of Internet network - fixedbroadband subscription charge, is negatively associated with IU changes, although 'statistically' its impact on growth on number of Internet users is relatively weaker than impact of prices on increasing usage of mobile cellular telephony (compare estimates for $\mathrm{FE}(1)$ in Tables 2 and 3). The latter may be, at least to some extent, explained by the fact that an access to the Internet network is often financed by institutions or private companies and thus is not directly associated with individual's affordability, as in case of mobile cellular telephony. Examining the estimated coefficients that variables like population density and urbanization rates hold, we see that their value just slightly differ (even including the returned r-squares) from these observed for mobile cellular telephony (compare $\mathrm{FE}(2)$ and $\mathrm{FE}(3)$ in Table 2). The latter may suggest that the role of population density and/or urbanization rate in fostering growth of Internet network usage is close to what was reported for mobile cellular telephony spread. Notably the diffusion of new technological solutions is highly facilitated in densely populated and urbanized areas. Looking at estimates of dynamic panel models, we find again that results for Internet penetration rates coincide with these reported for mobile cellular telephony. By introducing IU_lagged variable we intend to capture the network effects. Both for $\mathrm{DP}(1)$ and $\mathrm{DP}(2)$ the returned coefficients standing by IU_lagged variable are the same $(0,82$ and 0,81$)$, while the remaining variables lose their explanatory power.

\subsection{Discussion}

Considering the network externalities we wished to check for, our findings seem to speak in support of our initially set hypothesis that ICT diffusion is strongly affected (preconditioned) by the word-of-mount effect and hence emerging network effects drive the take-off along diffusion path and consequently enable rapid spread of new information and communication technologies (in our case - mobile cellular telephony and Internet network). Apparently densely populated and urbanized areas constitute a perfect prerequisite for dynamic diffusion of ICT as they allow for multiple interpersonal contacts and 'smooth' spread of new ideas among society members. When lagged values of MCS or IU are introduced to our panel models, the results are robust and stable unveiling that the 'installed base of previous' users of ICT is of the prime importance for diffusion of ICT. As we have already claimed in the conceptual section, positive network effects encourage broad, society-wide acceptance of a given new technology. Under uncertainty, which is inherent in system of diffusion, this unique externality makes people imitate the behavior of others to repeat choices made by innovators and/or early adopters. Henceforth, arguably we may claim that network effects demonstrate rather imitative effects, or imitative behavior, unveiled throughout the process of spread of new technologies. The positive feedback arises when society members tend to communicate among themselves, and due to various communication channels a stock of knowledge on advantages and benefits of new technology is transmitted. Moreover, all our findings support the fundamental idea that technology diffusion is dynamic, self-propagating and self-perpetuating process, in which certain regularities may be unveiled and described. 


\section{Conclusions}

This research contributed to the present state of the art by verifying the hypothesis on the existence of the network effects that due to random interpersonal contacts drive spread of new technologies among society members, which inevitably leads to rapidly increasing number of new adopter of new technological solutions. Despite the fact that the process of propagation of new technologies is strongly predetermined by multiple economic and institutional factors, arguably it is a social phenomenon demonstrating how social network may force diffusion of new technologies. With this aim we have selected 50 countries for which in 2016 the mobile cellular telephony penetration rates were the highest in the world, as these economies are perfect examples of how fast ICT may diffuse under favorable conditions and if enhanced by strong network effects. Henceforth we have concentrated on the process of analysis of two selected new technologies - mobile cellular telephony and Internet network, during the period 1990 and 2016. We have tested how strong ICT diffusion is subjected to the network effects by using panel and dynamic panel data model. Our depended variables were mobile cellular telephony and Internet network penetration rates; while as regressors we have set: costs of access to and use of ICT (approximated by prices of 1-minute call and fixed-broadband subscription charge), population density, urbanization rate and lagged values of MCS and IU in respective models). Our main findings confirm that both MCS and IU changes in variables are negatively associated with costs of access to and use of these technologies. Moreover, we have found that mobile cellular telephony and Internet networks spread was strongly positively associated with population density and urbanization rates. However, we have indentified the strongest statistical links when lagged values of depended variables were introduced to the models. By estimating the dynamic panel models we have found that lagged values of depended variables capture all variability of MCS and IU, while all the other regressors lose their explanatory power and result to be statistically insignificant. It must be emphasized that countries being in scope of this research are extremely heterogeneous and share very few common features. They differ in economic conditions and welfare (classical approximated by gross per capita income), level of social development and backbone infrastructure. We examine small poor economies - e.g. El Salvador, and small and very rich - e.g. Qatar; we have considered countries from all continents that vary hugely. All these 50 selected economies also differ in terms of religion, social norms and attitudes, legal and institutional frameworks or political regimes and freedoms. Differences matter as they potentially shape society`s readiness to acquire and put into usage new technologies. To a large extent, our major findings are remarkable, and they do confirm the main hypothesis that ICT diffusion is strongly endogenously driven process, and it is mainly subjected to unveiled network externalities, which, once emerged, give strong impulse for the fast and self-sustainable spread of new technology. This is crucial for a complete understanding the nature of new ICT.

Our study has shown that new technologies diffusion is heavily preconditioned by social dynamics and social attitudes towards acquiring technological novelties. It has clearly demonstrated that new information and communication technologies diffuse fast society-, and economy-wide, and this process is strictly preconditioned by emerging network effects that drive rapid technology propagation. At the same time we have confirmed the common statement that ICT are technologies 'for all' that omit all these barriers that effectively hindered diffusion of old-type technological solutions.

Finally, it should be underlined that examining these types of relationships is a challenging task. The relationship between ICT changing deployment and other social, economic or institutional determinants is neither direct nor immediate and significant time lags may emerge when considering the impact of certain determinants on diffusion of technological innovations. Despite the fact that econometric modeling is usually used to trace the relationship 
between different variables, one should mention that such approach is heavily biased and purely quantitative approach does not always give clear answer and all these shall be borne in mind while drawing conclusions and formulating recommendations based on the results presented and discusses here below.

\section{Acknowledgement}

This research has been supported by the project no.2015/19/B/HS4/03220 financed by the National Science Centre, Poland.

\section{References}

Arellano, M. (1987). PRACTITIONERS'CORNER: Computing Robust Standard Errors for Within-groups Estimators. Oxford bulletin of Economics and Statistics, 49(4), 431-434.

Baltagi, B. (2008). Econometric analysis of panel data. John Wiley \& Sons.

Bass, F. M. (1969). A new product growth for model consumer durables. Management science, 15(5), 215-227.

Bass, F. M. (1980). The relationship between diffusion rates, experience curves, and demand elasticities for consumer durable technological innovations. Journal of Business, S51S67.

Cabral, L. M. (1990). On the adoption of innovations with 'network' externalities. Mathematical Social Sciences, 19(3), 299-308.

Cleveland, W. S. (1979). Robust locally weighted regression and smoothing scatterplots. Journal of the American statistical association, 74(368), 829-836.

Comin, D., Hobijn, B., \& Rovito, E. (2006). Five facts you need to know about technology diffusion (No. w11928). National Bureau of Economic Research.

Cusumano, M. A., Mylonadis, Y., \& Rosenbloom, R. S. (1992). Strategic maneuvering and mass-market dynamics: The triumph of VHS over Beta. Business history review, 66(01), 51-94.

David, P. A. (1986). Technology diffusion, public policy, and industrial competitiveness. The positive sum strategy: Harnessing technology for economic growth, 373-391.

Dicken, P. (2007). Global shift: Mapping the changing contours of the world economy. SAGE Publications.

Economides, N. (1996). The economics of networks. International journal of industrial organization, 14(6), 673-699.

Fagerberg, J., Srholec, M., \& Verspagen, B. (2010). Innovation and economic development. Handbook of the Economics of Innovation, Elsevier, 2, 833-872.

Geroski, P. A. (2000). Models of technology diffusion. Research policy, 29(4), 603-625.

Granovetter, M. (1978). Threshold models of collective behavior. American journal of sociology, 1420-1443.

Greene, W. H. (2003). Econometric analysis. Pearson Education India.

Grübler, A. (1991). Diffusion: long-term patterns and discontinuities. In: Diffusion of Technologies and Social Behavior (pp. 451-482). Springer Berlin Heidelberg.

Katz, M. L., \& Shapiro, C. (1985). Network externalities, competition, and compatibility. The American economic review, 75(3), 424-440.

Kling, R. (2000). Learning about information technologies and social change: The contribution of social informatics. The information society, 16(3), 217-232.

Lechman, E. (2015). ICT Diffusion in Developing Countries: Towards a New Concept of Technological Takeoff. Springer. 
Lechman, E. (2017). The Diffusion of Information and Communication Technologies. Routledge.

Lee, M., Kim, K., \& Cho, Y. (2010). A study on the relationship between technology diffusion and new product diffusion. Technological Forecasting and Social Change, 77(5), 796802.

Loch, C. H., \& Huberman, B. A. (1999). A punctuated-equilibrium model of technology diffusion. Management Science, 45(2), 160-177.

MacKenzie, D., \& Wajcman, J. (1985). The social shaping of technology: how the refrigerator got its hum.

MacKenzie, D., \& Wajcman, J. (1999). The social shaping of technology. Open university press.

Mackay, H., \& Gillespie, G. (1992). Extending the social shaping of technology approach: ideology and appropriation. Social studies of science, 22(4), 685-716.

Mansfield, E. (1961). Technical change and the rate of imitation. Econometrica: Journal of the Econometric Society, 741-766.

Mansfield, E. (1971). Technological change:[an introduction to a vital area of modern economics. Norton.

Markus, M. L. (1987). Toward a "critical mass" theory of interactive media universal access, interdependence and diffusion. Communication research, 14(5), 491-511.

Mattsson, H. (2007). Locating biotech innovation: Places, flows and unruly processes. Uppsala University.

Mokyr, J. (1992). The lever of riches: Technological creativity and economic progress. Oxford University Press.

Mokyr, J. (2005). Long-term economic growth and the history of technology. Handbook of economic growth, Elsevier, pp. 1113-1180.

Peres, R., Muller, E., \& Mahajan, V. (2010). Innovation diffusion and new product growth models: A critical review and research directions. International Journal of Research in Marketing, 27(2), 91-106.

Rogers, E M. (1983). Diffusion of innovations. New York.

Rosenberg, N. (1974). Science, invention and economic growth. The Economic Journal, 84(333), 90-108.

Rosenberg, N. (1982). Inside the black box: Technology and economics. Cambridge University Press.

Saviotti, P. P. (2002). Black boxes and variety in the evolution of technologies. Economics of structural and technological change, 184-212.

Stoneman, P. (1983). The economic analysis of technological change. Oxford [Oxfordshire]; New York: Oxford University Press.

Stoneman, P. (2001). The economics of technological diffusion. Wiley-Blackwell.

Williams, R., \& Edge, D. (1996). The social shaping of technology. Research policy, 25(6), 865-899.

Valente, T. W. (1996). Social network thresholds in the diffusion of innovations. Social networks, 18(1), 69-89. 


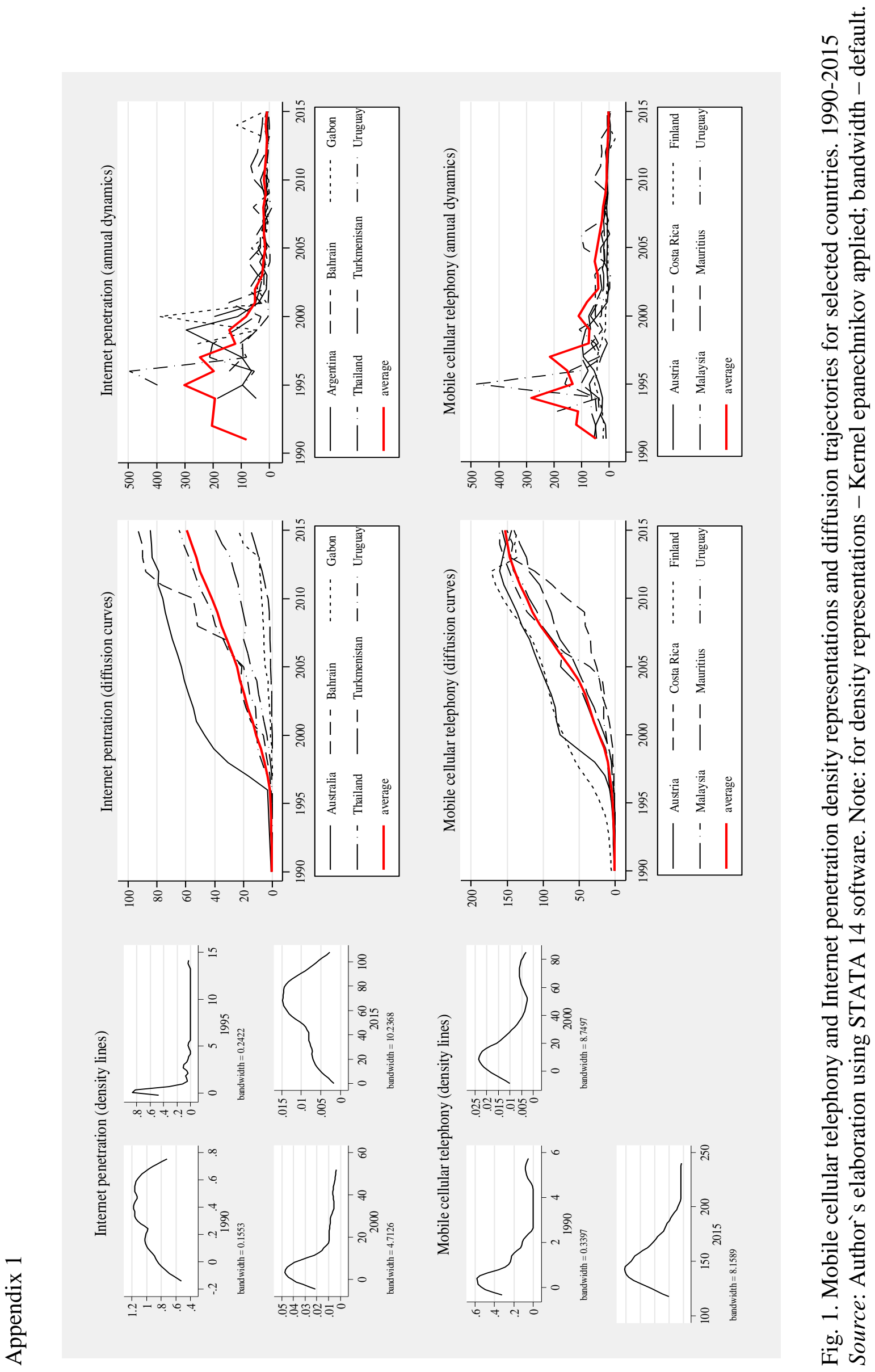


Appendix 2

ICT penetration rates in selected countries in 2015

\begin{tabular}{|c|c|c|}
\hline Country & Mobile cellular telephony & Internet users \\
\hline 1 & 2 & 3 \\
\hline Argentina & 143,9 & 69,4 \\
\hline Australia & 132,8 & 84,6 \\
\hline Austria & 157,4 & 83,9 \\
\hline Bahrain & 185,3 & 93,5 \\
\hline Botswana & 169,0 & 27,5 \\
\hline Cambodia & 133,0 & 19,0 \\
\hline Chile & 129,5 & 64,3 \\
\hline Costa Rica & 150,7 & 59,8 \\
\hline El Salvador & 145,3 & 26,9 \\
\hline Estonia & 148,7 & 88,4 \\
\hline Finland & 135,5 & 92,7 \\
\hline Gabon & 168,9 & 23,5 \\
\hline Gambia & 131,3 & 17,1 \\
\hline Ghana & 129,7 & 23,5 \\
\hline Indonesia & 132,3 & 22,0 \\
\hline Israel & 133,5 & 78,9 \\
\hline Italy & 151,3 & 65,6 \\
\hline Jordan & 179,4 & 53,4 \\
\hline Kazakhstan & 187,2 & 72,9 \\
\hline Kuwait & 231,8 & 82,1 \\
\hline Kyrgyzstan & 132,8 & 30,2 \\
\hline Libya & 157,0 & 19,0 \\
\hline Lithuania & 139,5 & 71,4 \\
\hline Luxembourg & 148,5 & 97,3 \\
\hline Malaysia & 143,9 & 71,1 \\
\hline Maldives & 206,7 & 54,5 \\
\hline Mali & 139,6 & 10,3 \\
\hline Malta & 129,3 & 76,2 \\
\hline Mauritius & 140,6 & 50,1 \\
\hline Montenegro & 162,2 & 64,6 \\
\hline Oman & 159,9 & 74,2 \\
\hline Panama & 174,2 & 51,2 \\
\hline Poland & 148,7 & 68,0 \\
\hline Qatar & 153,6 & 92,9 \\
\hline Russian Federation & 160,0 & 73,4 \\
\hline Saudi Arabia & 176,6 & 69,6 \\
\hline Seychelles & 158,1 & 58,1 \\
\hline Singapore & 146,1 & 82,1 \\
\hline South Africa & 159,3 & 51,9 \\
\hline Suriname & 180,7 & 42,8 \\
\hline Sweden & 130,4 & 90,6 \\
\hline Switzerland & 142,0 & 88,0 \\
\hline Thailand & 125,8 & 39,3 \\
\hline Trinidad \& Tobago & 157,7 & 69,2 \\
\hline Tunisia & 129,9 & 48,5 \\
\hline Turkmenistan & 145,9 & 15,0 \\
\hline
\end{tabular}




\begin{tabular}{lcc}
\hline \multicolumn{1}{c}{$l$} & 2 & 3 \\
\hline Ukraine & 144,0 & 49,3 \\
\hline United Arab Emirates & 187,3 & 91,2 \\
\hline Uruguay & 160,2 & 64,6 \\
\hline Viet Nam & 130,6 & 52,7 \\
\hline
\end{tabular}

Source: author`s compilation based on World Telecommunications / ICT Indicators database 2016. 